Reprod. Nutr. Dévelop., 1988, 28 (2 B), 515-526.

\title{
Entrainment of the rat pineal rhythm in melatonin production by light
}

\author{
Helena ILLNEROVÁ, J. VANĚČEK \\ with the technical assistance of Marie SVOBODOVÁ
}

Institute of Physiology, Czechoslovak Academy of Sciences, 14220 Prague 4, Czechoslovakia.

Summary. Environmental light entrains the rat pineal $\mathrm{N}$-acetyltransferase rhythm which controls melatonin production. One day after $1 \mathrm{~min}$ light pulses applied before midnight, or after delays in the evening switch off of light, or after a delay of the light-dark cycle, the evening $\mathrm{N}$-acetyltransferase rise and the morning decline are phase delayed almost to the same extent. Consequently, the pattern of the rhythm does not change. One day after 1 min light pulses applied past midnight, or after bringing forward the morning light onset, or after an advance of the light dark-cycle, the morning $\mathrm{N}$-acetyltransferase decline is phase advanced, but the evening rise is either not phase shifted or it may be even phase delayed. Consequently, the pattern of the rhythm may be changed considerably or the rhythm may be abolished. The data are consistent with an hypothesis of a two-component pacemaker controlling the $\mathrm{N}$-acetyltransferase rhythm. Under all photoperiods which we encounter in nature, the pattern of the $\mathrm{N}$-acetyltransferase rhythm is determined by the entraining effect of light on the pacemaker, but not by the suppressant effect of light.

\section{Introduction.}

In all animal mammalian species so far studied, the pattern of the rhythm in melatonin production and secretion depends on photoperiod (IIInerová, 1986) and may be involved in conveying the information on day length into organisms (Hoffmann et al., 1981 ; Bittman et al., 1983 ; Carter and Goldman, 1983). Our work deals with the way how the pattern is controlled by environmental light, namely by brief light pulses, prolonged periods of light, shifts in the light-dark cycle and photoperiods. For the most part, we studied the effect of light on the rat pineal $\mathrm{N}$-acetyltransferase (NAT) rhythm which drives the pineal melatonin rhythm (Klein and Weller, 1970 ; Illnerová et al., 1983). The NAT rhythm appears to be a very suitable overt rhythm for circadian studies. Its amplitude is very high: the nighttime NAT levels exceed the daytime ones by two orders of magnitude. Further, the NAT rhythm has two well defined phase markers : the time of the evening NAT rise and the time of the morning decline. It is possible to study motions of both phase markers already during the night when the circadian 
system is perturbed by light and in the subsequent days, during the so-called transient cycles, i.e. before the system attains a new steady-state. The phase relationship between both phase markers determines the period of elevated nighttime NAT activity and hence of high melatonin production.

The daily NAT and melatonin rhythms are circadian, as they persist even in a nonperiodic environment (Klein and Weller, 1970 ; Ralph et al., 1971). They are driven by a pacemaker located in the suprachiasmatic nuclei of the hypothalamus (Klein and Moore, 1979). A stimulatory phase for the NAT activity occurs apparently only at night (IIlnerová, 1974): norepinephrine is released from sympathetic nerve endings in the pineal at a higher rate and induces and activates NAT (Brownstein and Axelrod, 1974). Exposure of rats to light at night affects the melatonin metabolism (Illnerová, 1971). Both NAT activity and melatonin concentration decline rapidly (Deguchi and Axelrod, 1972 ; Klein and Weller, 1972 ; Illnerová et al., 1978). Light might block the stimulatory information. However, light may act also by entraining the NAT rhythm pacemaker, i.e. by phase shifting the stimulatory information. When light acts as the entraining agent, the phase shifts of the pacemaker persist even in the subsequent days and may be reflected in phase shifts of the overt NAT rhythm. Our attention will be focused on the entraining effect of light.

\section{Effect of brief light pulses.}

When rats maintained under an artificial lighting regime, with alternating $12 \mathrm{~h}$ of light and $12 \mathrm{~h}$ of darkness (LD 12 : 12), are exposed to a $1 \mathrm{~min}$ light pulse at various night times and thereafter are released into constant darkness to let the ryhthms become freerunning, the NAT rhythm in the subsequent nights is phase shifted relative to the rhythm in unpulsed controls (IIInerová, 1986 ; Illnerová and Vaněček, 1982a, b, 1983, 1987a). An example of phase shifts of the NAT rhythm during the night when the pulse is given before or past midnight, and after 1 and 4 days following the pulses presentation, is shown in Figure 1, upper part. Phase shifts of the evening NAT rise (E) and of the morning decline (M), determined from the upper part of Figure 1 and from other similar figures are summarized into the phase response curves (PRCs) (Fig. 1, lower part).

Following a light pulse applied before midnight, NAT activity after the initial decline and a lag period begins to increase anew to high night values as if the evening NAT rise were phase delayed. After 1 day, phase delays of the NAT rise are already of the same magnitude as after 4 days. Hence delays of the evening NAT rise are completed within one cycle. Following a light pulse applied past midnight, NAT activity declines rapidly and does not increase to high night values through the rest of the night as if the morning NAT decline were phase advanced. Phase advances of the decline after 1 and 4 days are of the same magnitude, hence advances of the morning NAT decline are completed within 1 cycle as well.

While phase delays of the evening NAT rise result in almost corresponding delays of the morning NAT decline already 1 cycle after a pulse presentation, it takes several transient cycles before phase advances of the decline begin to 
induce advances of the rise. Consequently, while after presentation of light pulses before midnight the next day the phase relationship between the evening NAT rise and the morning decline is only slightly shortened, after presentation of the pulses past midnight the phase relationship may be compressed considerably for at least 4 days.

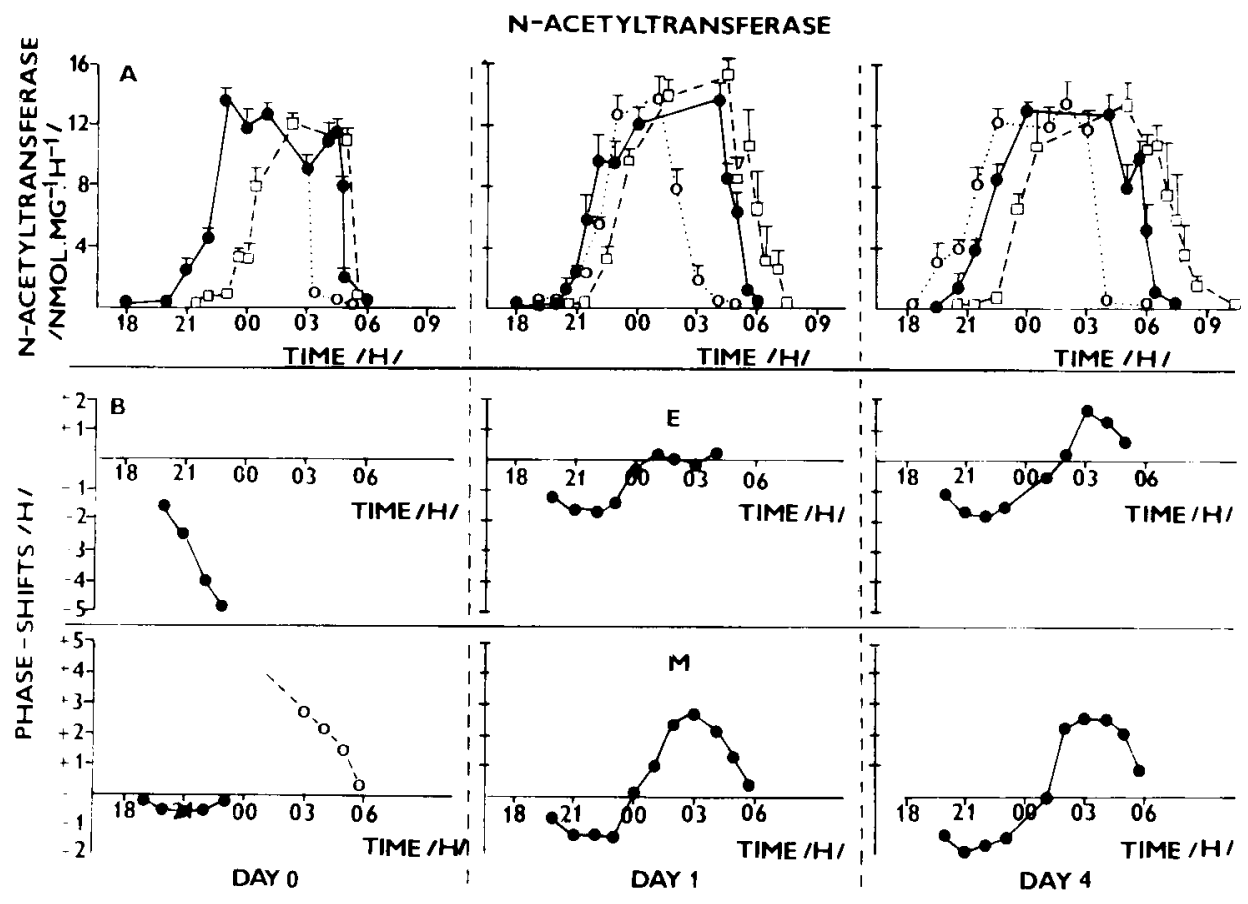

FIG. 1. - Entrainment of the $N$-acety/transferase rhythm by 1 min light pulses. Upper part: The rhythm after presentation of a light pulse at $21 \mathrm{~h}$ (open squares), or at $03 \mathrm{~h}$ (open circles). Rats maintained in LD $12: 12$, with lights on from $06 \mathrm{~h}$ to $18 \mathrm{~h}$, were either exposed to a $1 \mathrm{~min}$ light pulse or were left unpulsed (filled circles). Thereafter, they were released into constant darkness and killed during the night when they were pulsed (Day 0) or 1 (Day 1) or 4 (Day 4) days after the pulse presentation. Data, taken from Illnerová and Vaněček (1982a, 1983, 1987a) are expressed as means + SEM of four animals. Lower part: Phase response curves representing phase shifts of the evening $\mathrm{N}$-acetyltransferase rise (E) and of the morning decline (M) during the night when rats were pulsed and after 1 and 4 days. The phase shifts were determined at the level of $3 \mathrm{nmol} . \mathrm{mg}^{-1} \cdot \mathrm{h}^{-1}$ of $\mathrm{N}$-acetyltransferase activity from the upper part of the figure 1 and from other similar figures. Values of the phase shifts of the rise and decline (filled circles) and values of the suggested phase advances of the decline (open circles) were taken from Illnerová and Vaněček (1982a, b, 1987a). The abcissa denotes time of pulse presentation. Phase delays are expressed by the sign -, phase advances by the sign + .

\section{Effect of prolonged periods of light.}

In nature animals experience not just single brief pulses of light, but whole photoperiods as well. Hence it is necessary to study also the entrainment by prolonged periods of light, e.g. by delays in switching off the evening light or by bringing forward the morning light onset. 
When rats maintained under LD 12:12 are exposed to delays in the light switch off and thereafter they are released into constant darkness, the NAT rhythm is phase shifted relative to the rhythm in the rats subjected to the switch off of light at the usual time (Illnerová and Vaněček, 1987b). An example of phase shifts of the NAT rhythm during the night when the switch off of light was delayed by $4 \mathrm{~h}, 8 \mathrm{~h}$ and $10 \mathrm{~h}$, respectively, and during the next night, is shown in Figure 2, A. Phase shifts of the evening NAT rise (E) and of the morning decline (M), determined from Figure 2, A, and from other similar figures, are summarized into the PRCs (Fig. 2, B). When the evening switch off of light is delayed, the NAT rise during the same night is delayed almost proportionally, while the decline is delayed to a much lesser extent. Consequently, the phase relationship between the rise and the decline may be compressed considerably. The next day after delays in the evening light switch off, phase delays of the morning NAT decline are already almost of the same magnitude as phase delays of the evening rise.

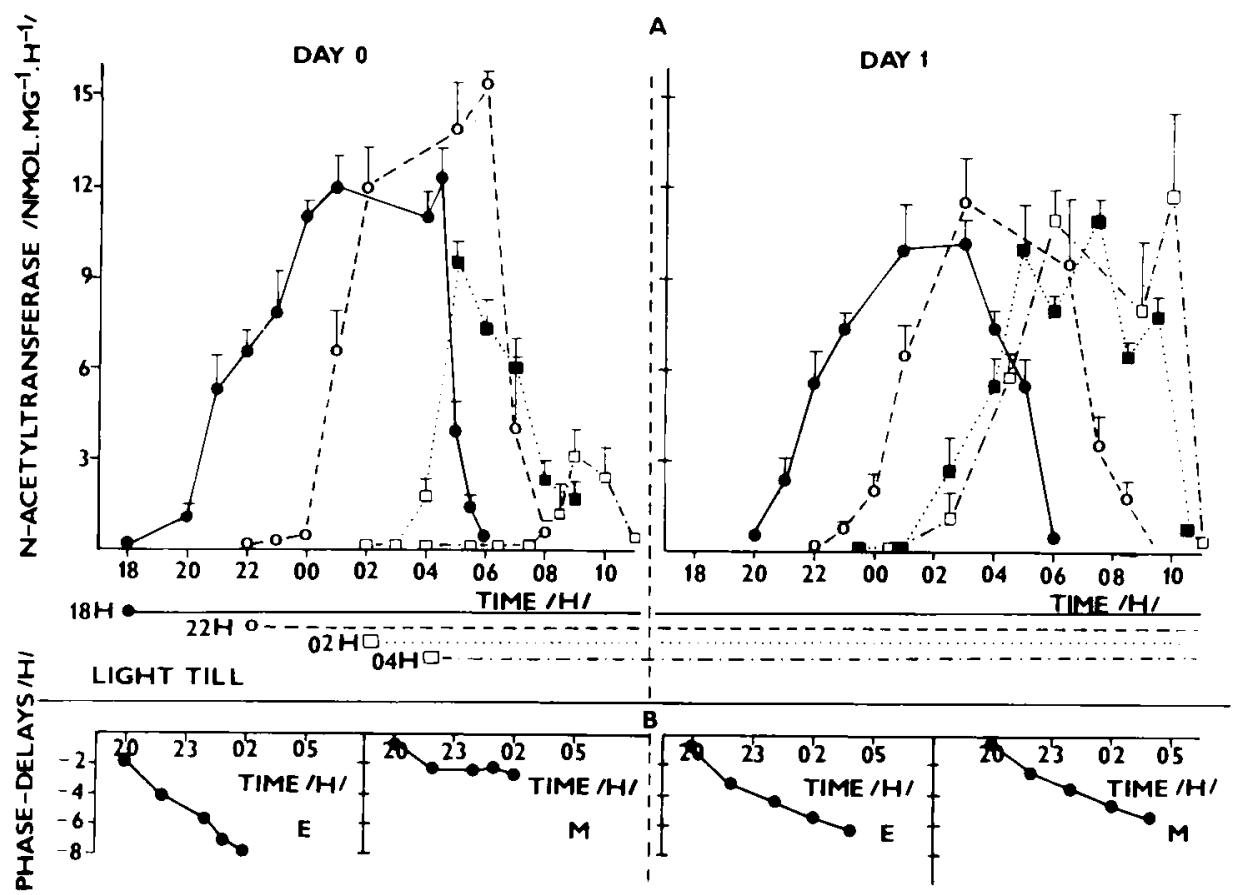

FIG. 2. - Entrainment of the $N$-acetyltransferase rhythm by delays in the evening light switch off. A. The rhythm during the night when the light switch off was delayed (Day 0 ) and during the next night (Day 1). Rats maintained in LD $12: 12$, with lights on from $06 \mathrm{~h}$ to $18 \mathrm{~h}$, were subjected either to the expected switch off of light at $18 \mathrm{~h}$ (filled circles), or to a delay in the light switch off till $22 \mathrm{~h}$ (open circles), $02 \mathrm{~h}$ (filled squares) and $04 \mathrm{~h}$ (open squares), respectively. Thereafter they were released into darkness. Data are expressed as means + SEM of four animals. Lines under the abcissa indicate dark periods. B. Phase response curves representing phase delays of the evening $\mathrm{N}$-acetyltransferase rise (E) and of the morning decline (M) during day 0 and 1 . The phase shifts of the experimental animals relative to the control ones were determined from Fig. $2 \mathrm{~A}$ and other similar figures (IIlnerová and Vaněcek, 1987b). The abcissa denotes time of the light switch off. 
Hence delays in the light switch off phase shift the NAT rhythm almost within 1 cycle and have a minimal effect on the pattern of the NAT rhythm the next days.

When rats maintained under LD $12: 12$ are subjected to bringing forward the morning onset of light and thereafter they are released into darkness at $14 \mathrm{~h}$ in order to allow expression of an eventual advance of the evening NAT rise, the NAT rhythm is phase shifted during the subsequent night relative to the rhythm in the rats subjected to the usual morning onset of light (Illnerová and Vaněček, 1987b). An example of the pattern of the NAT rhythm during the night when the morning light onset was brought forward by $3 \mathrm{~h}, 5 \mathrm{~h}$ and $7 \mathrm{~h}$, respectively, and during the next night, is shown in Figure 3, A. Phase shifts of the evening NAT rise (E) and of the morning decline (M) 1 day after bringing forward the light

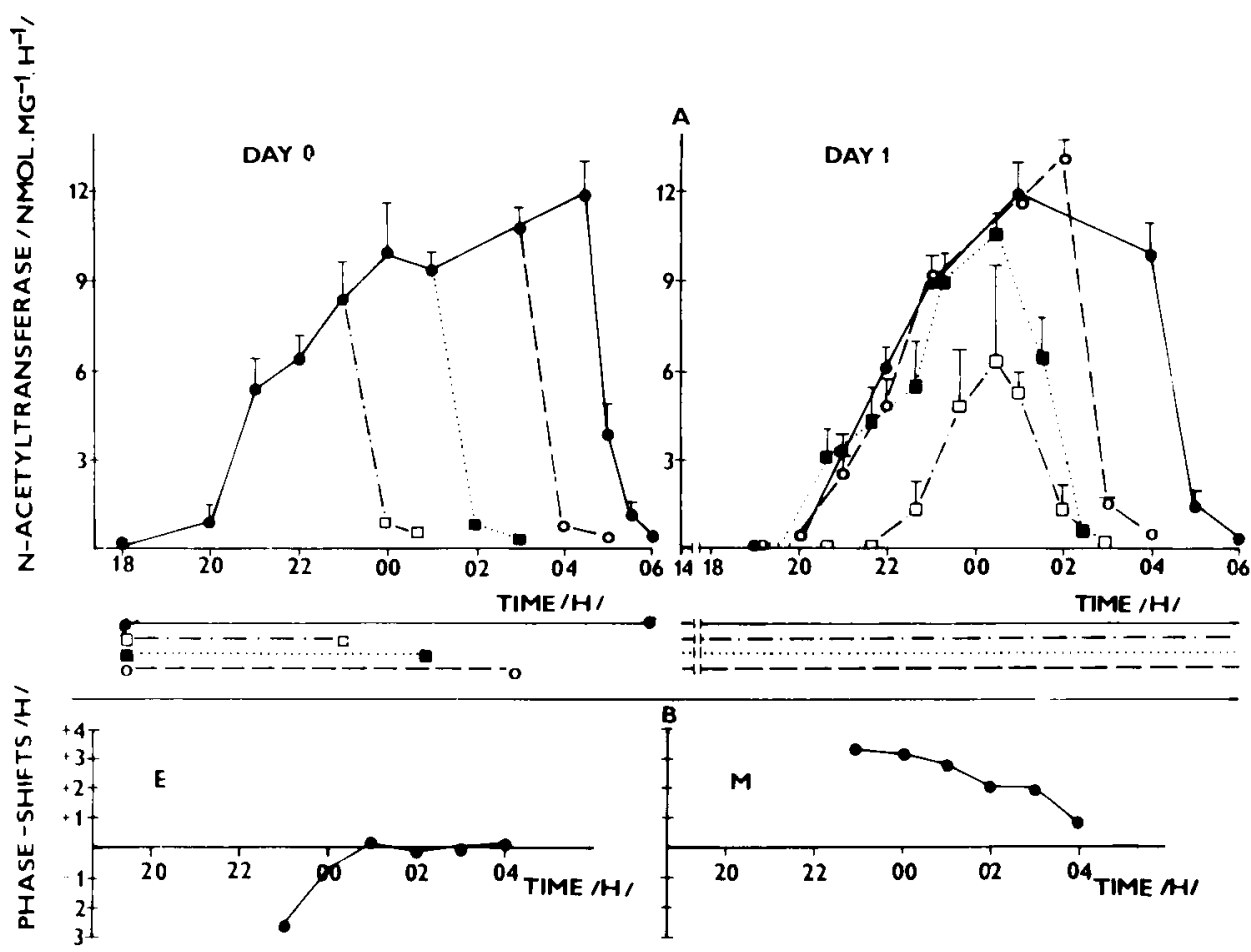

FIG. 3. - Entrainment of the $N$-acetyltransferase thythm by bringing forward the morning light onset. A. The rhythm during the night when the light onset was brought forward (Day 0 ) and during the next night (Day 1). Rats adapted to LD $12: 12$, with lights on from $06 \mathrm{~h}$ to $18 \mathrm{~h}$, were subjected to the usual light switch off at $18 \mathrm{~h}$ and later that night either to the usual morning onset of light at $06 \mathrm{~h}$ (filled circles), or to bringing it forward to $03 \mathrm{~h}$ (open circles), to $01 \mathrm{~h}$ (filled squares) and to $23 \mathrm{~h}$ (open squares), respectively (Day 0). Thereafter, light was turned off at $14 \mathrm{~h}$ and the rats were killed during the subsequent night (Day 1 ). Data are expressed as means + SEM of 4 to 8 animals. Lines under the abcissa indicate dark periods. B. Phase response curves representing phase shifts of the evening $N$-acetyltransferase rise (E) and of the morning decline (M) the next night after bringing forward the morning light onset (Day 1). The shifts were determined from Fig. 3, A and from other similar figures (IIInerová and Vaněček, 1987b). The abcissa denotes time of the morning light onset. Phase delays are expressed by the sign -, phase advances by the sign + . 
onset, determined from Figure 3, A and from other similar figures, are summarized into the PRCs (Fig. 3, B). Though after bringing forward the morning onset of light the NAT decline is advanced the next night, in no case the evening NAT rise is phase advanced. When the light onset is brought forward to before midnight, the next night the NAT rise is even phase delayed. The phase relationship between the NAT rise and the decline may be either drastically reduced or the rhythm may be almost abolished.

Brief light pulses and prolonged periods of light may affect the NAT rhythm similarly. Following pulses applied before midnight or after delays in the evening switch off of light, the next night the evening NAT rise and the morning decline are delayed almost to the same extent. Consequently, the NAT rhythm is phase shifted, but its pattern does not change. After delays in the evening light switch off, maximal phase delays of the NAT rhythm are 3 to 4 times larger than after presentation of light pulses. Following pulses applied past midnight or after bringing forward the light onset, the next night the morning decline is phase advanced, but the rise is either not phase shifted or it may be even phase delayed. Consequently, the pattern of the rhythm is affected considerably.

\section{Effect of shifts of the light-dark cycle.}

The data on the adjustment of the NAT rhythm to prolonged periods of light suggest that adaptation to a delay of the LD cycle, i.e. to a simulated westward time-zones transition, may be more rapid than adaptation to an advance of the LD cycle, i.e. to a simulated eastward time-zones transition. It seems to be really so. When rats maintained under LD $12: 12$ are subjected to a $8 \mathrm{~h}$ delay of the LD cycle by lengthening one light period by $8 \mathrm{~h}$, the NAT rhythm adjusts to the delay shift almost within one cycle (Fig. 4, lower part). The adjustment to the $8 \mathrm{~h}$ delay shift is accomplished by shifts of the evening NAT rise and of the morning decline in the same direction. A different picture appears when the LD regime is advanced by $8 \mathrm{~h}$ by shortening one dark period by $8 \mathrm{~h}$ (Fig. 4, upper part). The NAT rhythm adjusts to the advance shift within 5 cycles only; during the first 3 cycles the rhythm is abolished (IIlnerová et al., 1987). The advanced light period may not only phase advance the morning NAT decline, but also phase delay the evening NAT rise (Illnerová and Vaněček, 1987b). The adjustment of the NAT rhythm to the $8 \mathrm{~h}$ advance shift may thus be accomplished by shifts of the NAT rise and of the decline in opposite directions. The normal pattern of the rhythm may reappear when the evening and the morning phase markers regain their original phase relationship.

\section{Effect of photoperiods.}

The period of elevated nighttime NAT activity and hence of high melatonin production in rats is longer under short than under long photoperiods (IIInerová, 1986 ; Illnerová and Vaněcek, 1980, 1982b, 1985) (Fig. 5). The shorter duration of 


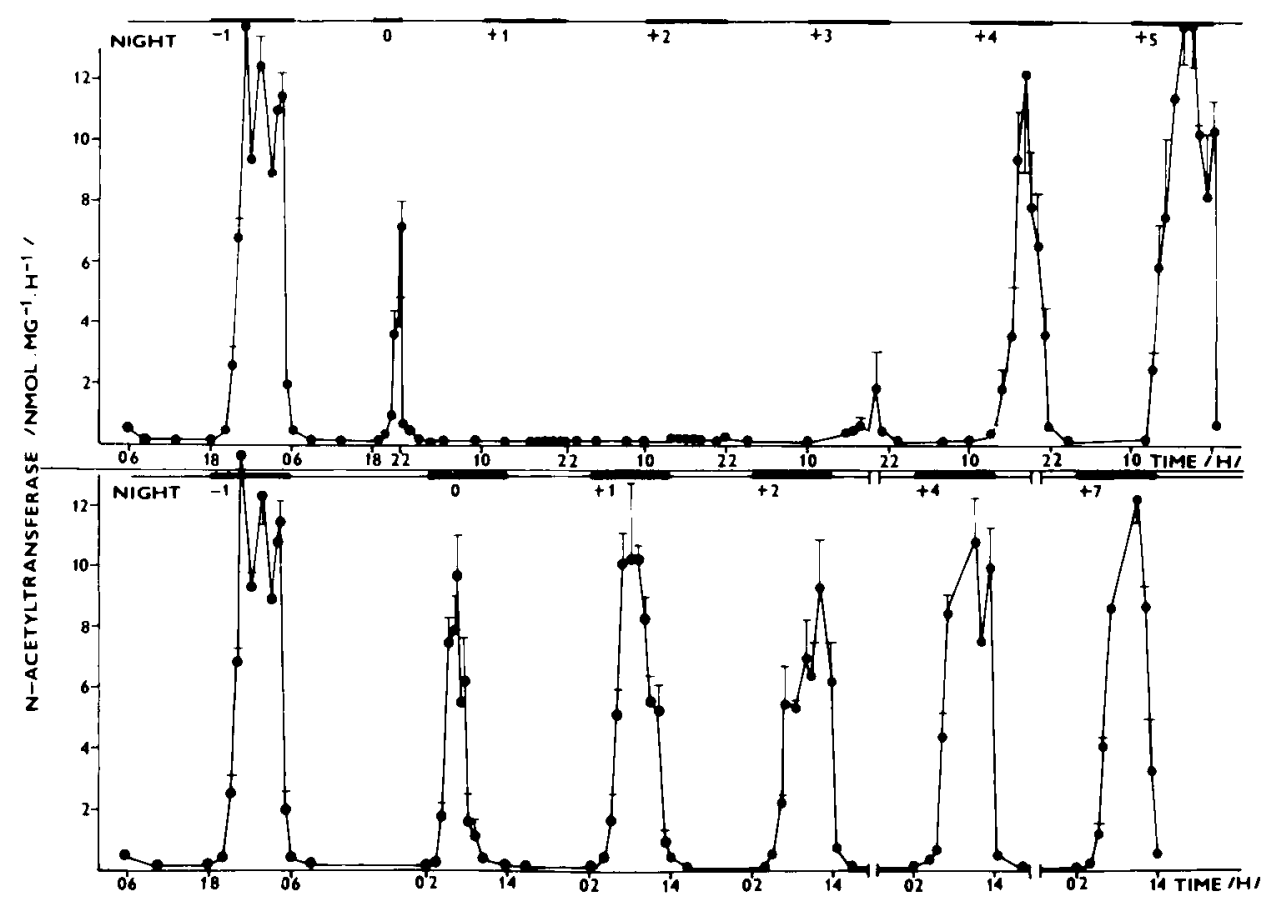

FIG. 4. - Adjustment of the $N$-acetyltransferase rhythm to a $8 \mathrm{~h}$ advance (upper part) and to a $8 \mathrm{~h}$ delay (lower part) of the light-dark cycle. Alternating black bars indicate dark periods and at the same time the schedule of advancing the light-dark cycle by shortening one dark period (upper part), and of delaying the cycle by lengthening one light period (lower part). Rats adapted to LD 12: 12 were killed during the night before the $8 \mathrm{~h}$ shifts (night -1 ), during the shifts (night 0 ), and during the subsequent nights. Data, taken from Illnerová et al. (1987), are expressed as means + SEM of 4 to 12 animals.

the period on long days may be explained by the entraining effect of light : the evening light may phase delay the NAT rise, the morning light may phase advance the decline. Consequently, the pattern of the NAT rhythm is compressed. In addition, the evening and the morning light might have also the suppressant effect on the rhythm in melatonin production (Lewy, 1983). However, the morning NAT decline occurs spontaneously before the light onset under all photoperiods which we may encounter in nature (Fig. 5). With the exception of LD $20: 4$, the morning light has solely the entraining effect. Under very short photoperiods, the evening light has neither a suppressant nor an entraining effect on the NAT rhythm (Illnerová and Vaněček, 1985). Under a mean photoperiod, i.e. under LD $12: 12$, the evening light has solely the entraining effect (IIInerová, 1986). Under LD $18: 6$, the NAT rise is advanced by $0.7 \mathrm{~h}$ when the switch off of light is brought forward by $7 \mathrm{~h}$ (Illnerova and Vaněček, 1985). However, light intruding into the late evening hours has a considerable phase delaying effect on the NAT rise (llinerová and Vaněček, 
1987b). Hence, even under LD $18: 6$, the evening light has rather the entraining effect. In conclusion, under all natural photoperiods the phase relationship between the evening NAT rise and the morning decline is determined by the entraining effect of light.

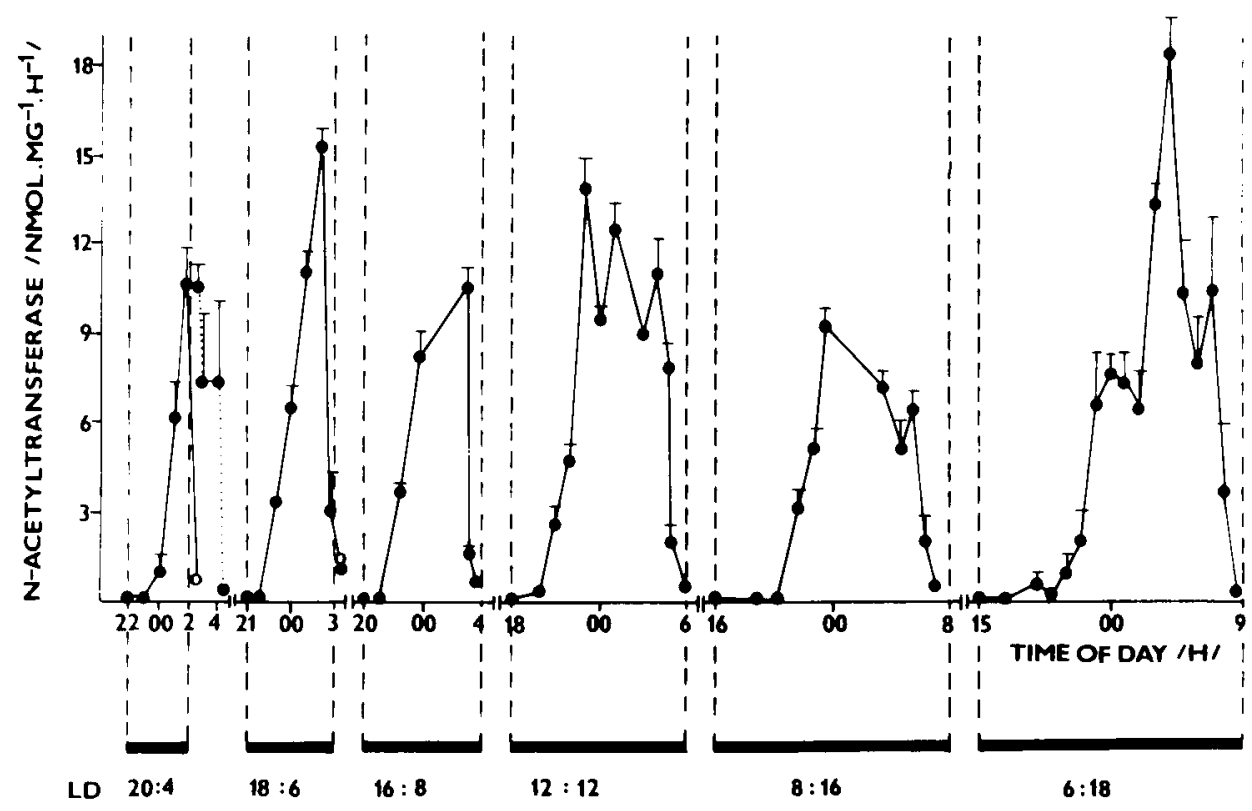

FIG. 5. - The rat pineal $N$-acety/transferase rhythm under various photoperiods. Black bars indicate dark periods. Filled circles represent animals killed in darkness, open circles animals killed in light. Data, taken from Illnerová and Vaněcek (1980; 1982b, 1985, unpublished results), are means + SEM of 4 rats.

The NAT rhythm is locked rather to the morning light onset than to the evening light switch off (Illnerová, 1986). At the end of the dark period, the pacemaker controlling the NAT rhythm is sensitive to the phase advancing effect of the morning light and may be reset by a light pulse under a long photoperiod with $18 \mathrm{~h}$ of light per day as well as under a very short photoperiod with only $6 \mathrm{~h}$ of light (Fig. 6) (Illnerová and Vaněček, 1985). At the beginning of the dark period, the pacemaker is sensitive to the phase delaying effect of the evening light under the long photoperiod only. It may be inferred that on longer days the NAT rhythm may be entrained by the morning as well as by the evening light, while on very short days it may be entrained by the morning light only and the phase relationship between the evening NAT rise and the morning decline may be stable. On longer days, the entrainment of the NAT rhythm is accomplished by smaller phase shifts than on shorter days (Fig. 6). 


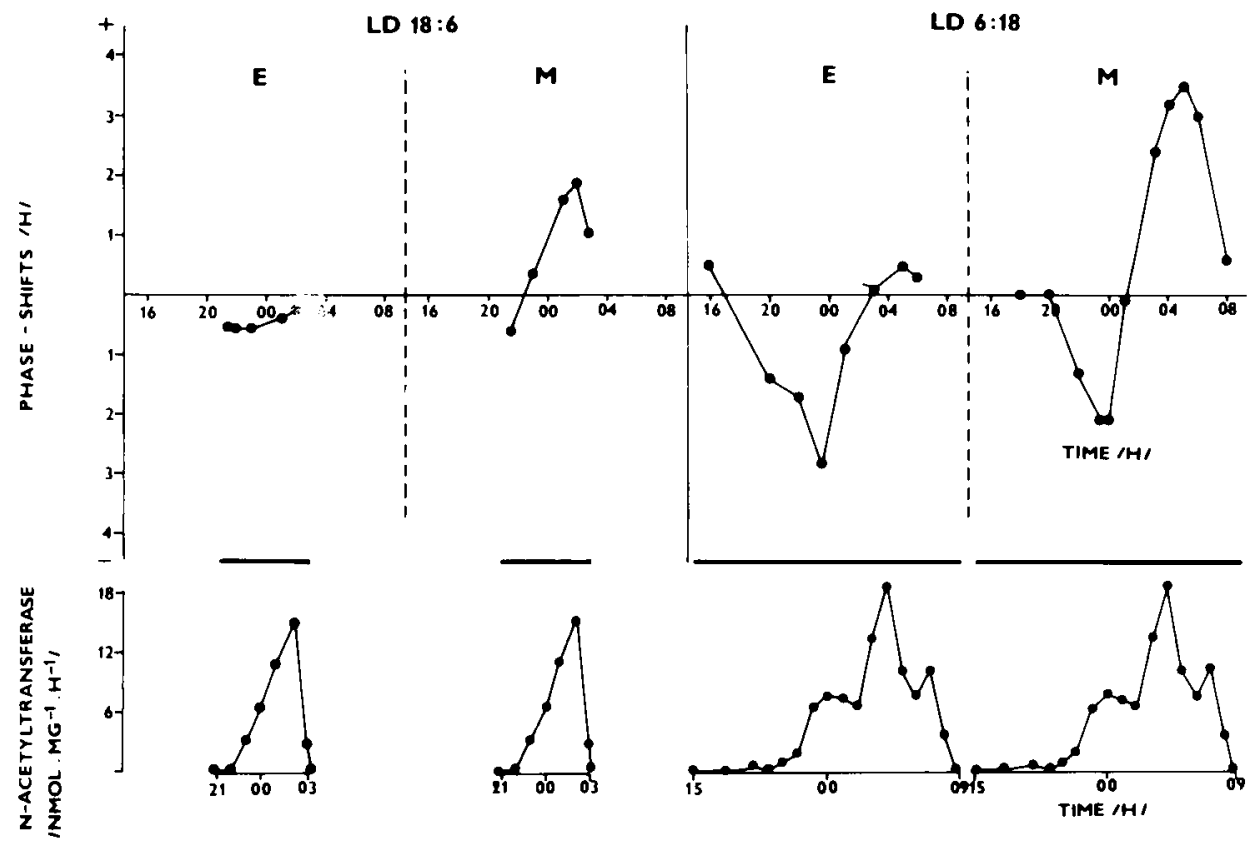

FIG. 6. - Entrainment of the $N$-acetyltransferase rhythm by brief light pulses under a long and a short photoperiod. Upper part: Phase response curves of the evening $\mathrm{N}$-acetyltransferase rise (E) and of the morning decline (M) one day after application of $1 \mathrm{~min}$ light pulses to rats maintained in LD $18: 6$ or in LD $6: 18$. Values of phase shifts were read from the graphic illustration of the $\mathrm{N}$-acetyltransferase rhythm in pulsed and unpulsed rats one day after presentation of a light pulse (IIInerová and Vaněček, 1985). Abcissa denotes time of pulse presentation. Delays are expressed by the sign - advances by the sign + . Lower part: The rhythm in LD 18:6 and LD $6: 18$.

\section{Effect of change of a photoperiod.}

The adjustment of the rat pineal NAT rhythm and of the Djungarian hamster melatonin rhythm to a change from a long photoperiod, LD $16: 8$, to a short photoperiod, LD $8: 16$, is a gradual process (Fig. 7) (Illnerová et al., 1984, 1986). In rats, the extension of the NAT rhythm pattern after a symmetrical prolongation of the dark period around midnight is accomplished within 6 days, in adult Djungarian hamsters it may not yet be completed within 6 weeks. In both these species, the extension of the phase relationship between the evening NAT and melatonin rise and the morning decline proceeds more rapidly after prolongation of the dark period into the morning than into the evening hours (Illnerova et al., 1986 ; Hoffmann and Illnerová, 1986). While the extension of the period of high nocturnal melatonin production is a gradual process, the compression of the period may proceed rapidly (IIInerová, 1986). Consequently, the lengthening of a photoperiod in rats and Djungarian hamsters may be recognized sooner than the shortening. 

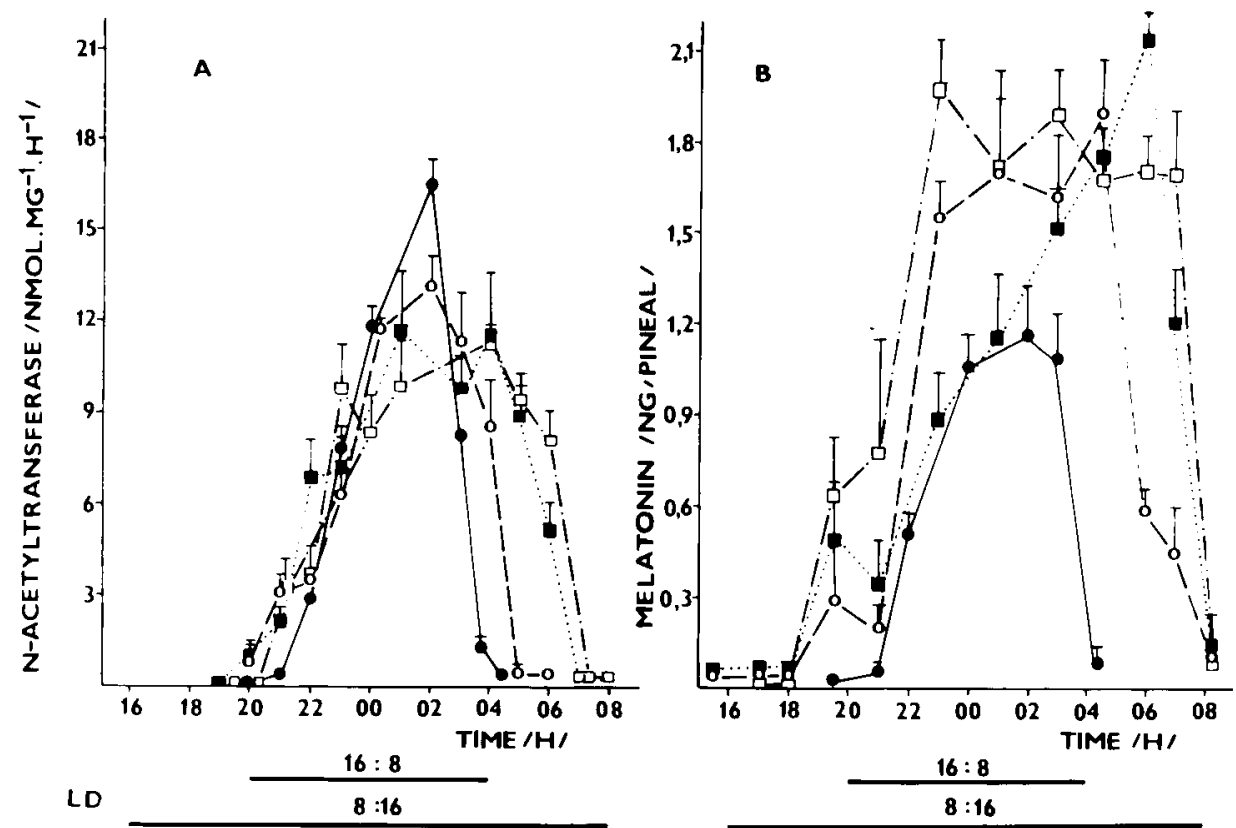

FIG. 7. - Adjustment of the $\mathrm{N}$-acetyltransferase rhythm in pineals of rats (A) and of the melatonin rhythm in pineals of Djungarian hamsters (B) to the change from $\angle D 16: 8$ to $L D 8: 16$. Animals maintained in LD $16: 8$ were either killed in LD $16: 8$ (filled circles), or were transferred to LD $8: 16$, with the dark period extended symmetrically around midnight, and killed A. 3 lopen circles), 6 (filled squares) and 13 (open squares) days later and B. 2 (open circles), 4 (filled squares) and 6 (open squares) weeks later, respectively. Data, taken from Illnerová et al. (1984, 1986 ), are expressed as means + SEM of $4-5$ animals. Lines below the abcissa denote periods of darkness before (LD $16: 8$ ) and after (LD $8: 16$ ) transfer.

\section{Conclusion.}

The evening NAT rise and the morning NAT decline not only do not phase shift always in parallel, but they may even phase shift in opposite directions. This behaviour may be consistent with a hypothesis of a complex, two-component, pacemaker controlling the NAT rhythm (IIInerová and Vaněček, 1982a, b), such as was proposed originally by Pittendrigh and Daan (1976) for the locomotor activity rhythm in nocturnal rodents. An evening component, $E$, may control the NAT rise and be the primary responder to the evening light, while a morning component, $\mathrm{M}$, may control the NAT decline and be the primary responder to the morning light. The phase relationship between $E$ and $M$ determines the period of elevated NAT activity and hence of high nocturnal melatonin production. The precise circadian control of the phase relationship between $E$ and $M$ and of the phase of the NAT rhythm may be involved in the photoperiodic time measurement and in the entrainment of the whole circadian system.

Colloquium on " Neuroendocrine mechanisms and light control of reproduction in domestic mammals " I.N.R.A., Nouzilly, 17-18 September 1987. 
Acknowledgements. - We thank Mrs Marie Svobodová for her excellent technical assistance and Dr Magda Kramperová for kindly typing the manuscript.

Résumé. Entraînement du rythme de production de la mélatonine par la lumière dans la glande pinéale du rat.

L'environnement lumineux entraîne, dans la glande pinéale du rat, le rythme d'activité de la N-acétyltransférase (NAT) qui contrôle la sécrétion de mélatonine.

Un jour après un pulse lumineux de 1 min appliqué avant minuit, ou après des retards dans l'extinction de la lumière le soir, ou encore après un retard du cycle lumière-obscurité, l'élévation de la NAT le soir et sa diminution le matin ont un retard de phase presque de la même durée. En conséquence, la cinétique du rythme ne change pas.

Un jour après un pulse lumineux de 1 min appliqué après minuit, ou après avancement de l'éclairement le matin, ou après une avance dans le cycle obscurité-lumière, la diminution matinale de la NAT est avancée mais l'élévation du soir, soit ne présente pas de changement de phase, soit présente un retard de phase. En conséquence, la cinétique du rythme peut être modifiée considérablement ou le rythme peut même être supprimé. Nos données confortent l'hypothèse d'un pacemaker à deux composantes contrôlant le rythme de la NAT. Sous toutes les photopériodes que nous avons rencontrées dans la nature, la cinétique du rythme de la NAT est déterminée par l'effet d'entraînement de la lumière sur le pacemaker, mais pas par son effet inhibiteur.

\section{References}

BITTMAN E. L., DEMPSEY R. J., KARSCH F. J., 1983. Pineal melatonin secretion drives the reproductive response to daylength in the ewe. Endocrinology, 113, 2276-2283.

BROWNSTEIN M., AXELROD J., 1974. Pineal gland : 24-hour rhythm in norepinephrine turnover. Science, 184, 163-165.

CARTER D. S., GOLDMAN B. D., 1983. Antigonadal effects of timed melatonin infusion in pinealectomized male Djungarian hamsters (Phodopus sungorus sungorus): Duration is the critical parameter. Endocrinology, 113, 1261-1267.

DEGUCHI T., AXELROD J., 1972. Control of circadian change in serotonin $\mathrm{N}$-acetyltransferase activity in the pineal organ by the beta-adrenergic receptor. Proc. nat. Acad. Sci. USA, 69, 2547-2550.

HOFFMANN K., ILLNEROVA H., 1986. Photoperiodic effects in the Djungarian hamster. Neuroendocrinology, 43, 317-321.

HOFFMANN K., ILLNEROVA H., VANĚČEK J., 1981. Effect of photoperiod and of one minute light at night-time on the pineal rhythm in $\mathrm{N}$-acetyltransferase in the Djungarian hamster Phodopus sungorus. Biol. Reprod., 24, 551-556.

ILLNEROVA H., 1971. Effect of light on the serotonin content in the pineal gland. Life Sci, 10, Part I, 955-960.

ILLNEROVÁ H., 1974. The effect of darkness and pargyline on the activity of serotonin $N$ acetyltransferase in the rat epiphysis. Neuroendocrinology, 16, 202-211.

ILLNEROVA H., 1986. Circadian rhythms in the mammalian pineal gland, pp. 1-105. Academia, Praha.

ILLNEROVÁ H., VANĚČEK J., 1980. Pineal rhythm in N-acetyltransferase activity in rats under different artificial photoperiods and in natural daylight in the course of a year. Neuroendocrinology 31, 321-326.

ILLNEROVA H., VANĚCEK J., 1982a. Two-oscillator structure of the pacemaker controlling the circadian rhythm of $\mathrm{N}$-acetyltransferase in the rat pineal gland. J. comp. Physiol., 145, 539-548.

ILLNEROVA H., VANĚČK J., 1982b. Complex control of the circadian rhythm in N-acetyltransferase activity in the rat pineal gland. In Vertebrate circadian systems, pp. 285-296. Eds J. ASCHOFF, S. DAAN and G. GROOS. Springer Verlag, Berlin and Heidelberg. 
ILLNEROVÁ H., VANĚČEK J., 1983. Extension of the rat pineal $\mathrm{N}$-acetyltransferase rhythm in continuous darkness and on short photoperiod. Brain Res., 261, 176-179.

ILLNEROVÁ H., VANĚCEK J., 1985. Entrainment of the circadian rhythm in rat pineal $\mathrm{N}$-acetyltransferase activity under extremely long and short photoperiods. J. Pineal Res., 2, 67-78.

ILLNEROVÁ H., VANĚCEK J., 1987a. Dynamics of discrete entrainment of the circadian rhythm in the rat pineal $\mathrm{N}$-acetyltransferase activity during transient cycles. J. biol. Rhythms, 2, 95-108.

ILLNEROVÁ H., VANĚČEK J., 1987b. Entrainment of the circadian rhythm in the rat pineal N-acetyltransferase activity by prolonged periods of light. J. comp. Physiol., A, 161, 495-510.

ILLNEROVA H., BÄCKSTROM M., SÄÄF J., WETTERBERG L., VANGBO B., 1978. Melatonin in the rat pineal and serum : rapid parallel decline after light exposure at night. Neurosci. Lett., 3, 189-193.

ILLNEROVÁ H., HOFFMANN K., VANĚČEK J., 1984. Adjustment of pineal melatonin and N-acetyltransferase rhythms to change from long to short photoperiod in the Djungarian hamster Phodopus sungorus. Neuroendocrinology, 38, 226-231.

ILLNEROVA H., HOFFMANN K., VANĚČEK J., 1986. Adjustment of the rat pineal N-acetyltransferase rhythm to change from long to short photoperiod depends on the direction of extension of the dark period. Brain Res., 362, 403-408.

ILLNEROVA H., VANĚČEK J., HOFFMANN K., 1983. Regulation of the pineal melatonin concentration in the rat (Rattus norvegicus) and in the Djungarian hamster (Phodopus sungorus). Comp. Biochem. Physiol., 74, 155-159.

ILLNEROVÁ H., VANĚČEK J., HOFFMANN K., 1987. Adjustment of the rat pineal $\mathrm{N}$-acetyltransferase rhythm to 8 hour shifts of the light-dark cycle : advance of the cycle disturbs the rhythm more than delay. Brain Res., 417, 167-171.

KLEIN D. C., MOORE R. J., 1979. Pineal N-acetyltransferase and hydroxyindole-O-methyltransferase : Control by the retinal hypothalamic tract and the suprachiasmatic nucleus. Brain Res., 174, 245-262.

KLEIN D. C., WELLER J. L., 1970. Indole metabolism in the pineal gland. A circadian rhythm in $\mathrm{N}$-acetyltransferase activity. Science, 169, 1093-1095.

KLEIN D. C. and WELLER J. L., 1972. Rapid light-induced decrease in pineal serotonin N-acetyltransferase. Science, 177, 532-533.

LEWY A. J., 1983. Biochemistry and regulation of mammalian melatonin production. In The Pinea/ gland, pp. 77-128. Ed. R. M. RELKIN, Elsevier, North Holland, Amsterdam.

PITTENDRIGH C. S., DAAN S., 1976. A functional analysis of circadian pacemakers in nocturnal rodents. V. Pacemaker structure : A clock for all seasons. J. comp. Physiol., 106, 333-355.

RALPH C. L., HULL D., LYNCH H. J., HEDLUND L., 1971. A melatonin rhythm persists in rat pineals in darkness. Endocrinology, 89, 1361-1366. 